\title{
Effects of Dietary Available Phosphorus Levels and Phytase Supplementation on Performance, Egg Quality and Serum Biochemical Parameters of Hy-Line Brown Laying Hens from 40 to 60 Weeks of Age
}

\author{
Chun Ik Lim ${ }^{1}$, Md Masud Rana ${ }^{1}$, Hwan $\mathrm{Ku} \mathrm{Kang}^{2}$ and Kyeong Seon Ryu ${ }^{3^{+}}$ \\ ${ }^{I}$ Researcher, Department of Animal Science, Chonbuk National University, Jeonju 54896, Republic of Korea \\ ${ }^{2}$ Researcher, Poultry Research Institute, National Institute of Animal Science, RDA, Pyeongchang 25342, Republic of Korea \\ ${ }^{3}$ Professor, Department of Animal Science, Chonbuk National University, Jeonju 54896, Republic of Korea
}

\begin{abstract}
This study was performed to evaluate the effects of available phosphorus (AP) levels with or without supplemental phytase on the performance, egg quality, and serum biochemical parameters of laying hens. A total of 540 laying hens (40-week-old) were housed in cages and assigned to 6 dietary treatments with 5 replicates each, for 20 weeks. The treatments consisted of $0.20 \%, 0.25 \%$, and $0.30 \%$ AP diets with or without phytase supplementation. During the 20 -week period, egg production was lowest in hens fed the $0.20 \%$ AP diet; however, phytase supplementation in the diet completely corrected the adverse effect $(P<0.05)$. No consistent difference was observed in egg production between hens fed the $0.25 \%$ and $0.30 \%$ AP diets and those fed the $0.20 \%$ and $0.30 \%$ AP diets with phytase supplementation. Similarly, egg mass was lowest in the $0.20 \%$ AP diet-fed group, and no difference in egg mass was observed in the $0.25 \%$ and $0.30 \%$ AP diet as well as the phytase-supplemented diet groups; however, egg mass was improved in the phytase-supplemented diet groups $(P<0.05)$. Egg quality traits did not differ with dietary treatments. Serum alkaline phosphatase level showed a linear decrease $(P<0.05)$ in the phytase-treated groups with increasing AP levels; moreover, a numerically linear increase $(P<0.05)$ in serum $\mathrm{Ca}$ and $\mathrm{P}$ levels was observed in the phytase-treated groups. The results of this study indicate that phytase supplementation in the diet of laying hens could increase egg production and may lead to greater mineral absorption.
\end{abstract}

(Key words: performance, egg quality, serum biochemical, available phosphorus, phytase)

\section{INTRODUCTION}

Phytic acid (myo-inositol hexakis-dihydrogenphosphate, IP6) is a ubiquitous compound that is abundant in plant source feed ingredients (cereal grains and oilseeds), serving as the major storage form of phosphorus $(\mathrm{P})$. According to the literature, about two-thirds of the total $\mathrm{P}$ in these plant source materials is present as the form of phytate which are salts of phytic acid and act as an anti-nutritional element (Jing et al., 2018). Phytic acid is an unwanted dietary agent and carries a strong negative charge thereby cause it make easily chelates form with these nutrient elements not only macro-micro minerals such $\mathrm{Ca}, \mathrm{Fe}, \mathrm{Zn}, \mathrm{Mg}, \mathrm{Mn}, \mathrm{Cu}$ and $\mathrm{Co}$ but also some other organic components like proteins and carbohydrates (Cowieson et al., 2009). Due to chelating nature with nutrients phytate limits the availability of minerals and other dietary nutrients in monogastric animals because of which poor phytate hydrolyzing enzymes called phytase present in the gastrointestinal tract; therefore, the effect of phytase supplementation in the diet of monogastric animals is being extensively investigated (Adeola and Cowieson, 2011). The beneficial effects of phytase as an additive in the diet which can hydrolyze phytate-bound components as a result may have improve performance and nutrient utilization by increasing metabolic activity and digestibility of monogastric animals (Butani and Parnerkar, 2015). In recent years, a series of studies have shown that phytase has a potent ability to liberate the anti-nutritional effect of phytate and improve the digestibility of phytate-bound $\mathrm{P}, \mathrm{Ca}$ amino acids and energy as well as minimize of excess $\mathrm{P}$ excretion to the environment (Dersjant-li et al., 2015). Additionally, observed results of previous study on laying hens indicated that the supplemen-

${ }^{\dagger}$ To whom correspondence should be addressed : seon@jbnu.ac.kr 
tation of phytase in the diet of laying hens had improved egg production, egg quality, nutrient digestibility, and retention of minerals (Panda et al., 2005; Gao et al., 2013; Englmaierova et al., 2014; Rojas et al., 2017). Moreover, the use of exogenous phytase as a feed additive to poultry diet may partially or completely minimize nutrient variability of feedstuffs by reducing the cost of nutritional inputs, as example, by replacing inorganic source such as dicalcium phosphate and increase the accuracy of feed formulation (Sousa et al., 2015), as well as leads to reduction of $P$ excretion in the environment (Slominski, 2011). However, although a number of studies have already been carried out to investigate the potentiality of phytase use as feed additive in laying hens diet to extended persistency of lay after end of peak but there were no general resemble till indicated among the research findings about concerning between the dietary AP requirements and addition of phytase on laying hens, even, there have very sparse information concerning the effect of phytase addition in laying hens diet on the serum biochemistry variables. Thus, the purpose of this study was to investigate the effect of AP levels with or without supplemental phytase on performance, egg quality and serum biochemical parameters of Hy-line brown laying hens from 40 to 60 weeks of age.

\section{MATERIALS AND METHODS}

\section{Experimental Design and Diets}

The experimental procedure was performed following the guidelines for the use of animals in experimentation, as provided by the Jeonbuk National University, Republic of Korea. A total of 540 Hy-line brown laying hens aged at 38 weeks of age, obtained from a commercial source, were placed in a poultry house in conventional type three-tier cages (two hens per cage). The cage dimensions were $30 \mathrm{~cm}$ $\times 40 \mathrm{~cm}$, equating to $1,200 \mathrm{~cm}^{2}$ floor space per cage. During the pre-experimental period from 38 to 40 weeks of age, hens were kept in the house for the acclimatization and were fed a common conventional layer mash diet and, the egg production recorded daily and eggs were weighed two times in a week.
Thereafter, at the age of 40 weeks, the hens (similar mean egg production of hens) were randomly assigned into 1 of 6 dietary treatments, each comprising five replicates and eighteen hens in each replicate in a completely randomized design. A replicate consisted of three adjacent cages in upper and alike in middle and bottom to minimize the cage level effect. The cages were equipped with trough feeder and nipple drinker line. A continuous feed trough was divided as the replicate as if hens were not able to consume feed assigned to the adjoining replicate. Three isoenergetic $(2,750$ $\mathrm{kcal} / \mathrm{kg} \mathrm{ME})$ and isonitrogenous $(16.0 \% \mathrm{CP})$ diets were formulated to contain three levels of $0.20,0.25$ and $0.30 \%$ AP respectively, and with or without phytase (1,000 FTU per kg diet, Ronozyme Hiphos-L, Aspergillus oryzae 6-phytase) was supplemented. A constant level of $4.0 \% \mathrm{Ca}$ was maintained in all dietary treatments and other dietary nutrients were fulfilled as the requirement of laying hen by the following specification of NRC (1994). During the experiment, hens under all treatment groups were given free access to mash type feed and water, and were exposed to a 16L: 8D lighting schedule. The mortality was replaced by spare hens kept upon on identical treatments throughout the experimental period. The composition of ingredients and chemical analysis of the basal diets are presented in Table 1.

\section{Performance of Laying Hens}

Laying performance of hens was determined at the end of every four weeks by monitoring egg production, egg weight, egg mass, feed intake and feed conversion ratio. Egg production was recorded daily which was expressed on a hen-day basis (\% hen-day) at the end of each four weeks. Eggs were collected two times in a week and the weight was taken to calculate mean egg weight. Egg mass (g/hen/day) was calculated by multiplying egg weight by egg production. Feed intake was determined at the end of four weeks as the replicate basis of each treatment by subtracting the remaining feed from the original amount of feed that was provided. Feed conversion ratio was calculated on the basis of amount of feed intake in gram divided by egg mass in gram.

\section{Egg Quality}

Thirty eggs from each dietary treatment group were arbitrarily selected at 44, 48, 52, 56 and 60 weeks of age to 
Table 1. The ingredient and nutrient composition of experimental diets

\begin{tabular}{|c|c|c|c|}
\hline \multirow{2}{*}{ Items } & \multicolumn{3}{|c|}{$\%$ of available phosphorus (AP) in the diet } \\
\hline & 0.20 & 0.25 & 0.30 \\
\hline \multicolumn{4}{|l|}{ Ingredient $(\%)$} \\
\hline Corn & 55.700 & 55.550 & 55.400 \\
\hline Wheat HRW & 3.820 & 3.555 & 3.290 \\
\hline Wheat bran & 10.220 & 10.505 & 10.790 \\
\hline Soybean meal $(48 \%)$ & 19.370 & 19.370 & 19.370 \\
\hline Monocalcium phosphate (Ca 18\%, P 21\%) & 0.630 & 0.875 & 1.120 \\
\hline Limestone (Ca 38.5\%) & 9.660 & 9.545 & 9.430 \\
\hline Iodized salt & 0.300 & 0.300 & 0.300 \\
\hline DL-Methionine (99\%) & 0.100 & 0.100 & 0.100 \\
\hline Vitamin premix & 0.100 & 0.100 & 0.100 \\
\hline Mineral premix & 0.100 & 0.100 & 0.100 \\
\hline Total & 100 & 100 & 100 \\
\hline \multicolumn{4}{|l|}{ Calculated nutrient composition } \\
\hline Metabolizable energy (kcal/kg) & 2,750 & 2,750 & 2,750 \\
\hline Crude protein $(\%)$ & 16.00 & 16.00 & 16.00 \\
\hline Calcium (\%) & 4.00 & 4.00 & 4.00 \\
\hline Total phosphorus (\%) & 0.59 & 0.64 & 0.70 \\
\hline Available phosphorus (\%) & 0.20 & 0.25 & 0.30 \\
\hline Lysine (\%) & 0.80 & 0.80 & 0.80 \\
\hline Methionine (\%) & 0.36 & 0.36 & 0.36 \\
\hline Cysteine (\%) & 0.29 & 0.29 & 0.29 \\
\hline Arginine $(\%)$ & 0.99 & 0.99 & 0.99 \\
\hline
\end{tabular}

${ }^{1}$ Vitamin supplement provided per kilogram of diet: vitamin $\mathrm{A}, 10,000 \mathrm{IU}$; vitamin $\mathrm{D}_{3}, 2,500 \mathrm{IU}$; vitamin $\mathrm{E}, 20 \mathrm{IU}$; vitamin $\mathrm{B}_{1}, 1.5 \mathrm{mg}$; vitamin $\mathrm{B}_{2}, 5.0 \mathrm{mg}$; vitamin $\mathrm{B}_{6}, 0.15 \mathrm{mg}$; vitamin $\mathrm{B}_{12} 15.0 \mathrm{mg}$; choline, $300 \mathrm{mg}$; pantothenate, $12 \mathrm{mg}$; nicotinic acid, $50 \mathrm{mg}$; biotin, $0.15 \mathrm{mg}$; folic acid, $1.5 \mathrm{mg}$.

${ }^{2}$ Mineral supplemented provided per kilogram of diet: Fe, $60 \mathrm{mg}, \mathrm{Cu}, 10 \mathrm{mg} ; \mathrm{Zn}, 80 \mathrm{mg}$; Mn, $110 \mathrm{mg}$; Iodine, $0.48 \mathrm{mg}$; Se, $0.40 \mathrm{mg}$.

estimate egg quality parameters. The egg quality parameters in terms of egg shell breaking strength, egg shell thickness, albumen height and Haugh unit were measured. Egg shell breaking strength was measured by egg shell strength tester (QC-SPA shell strength analyzer, TSS, UK) and the maximum force required to crack the shell surface was recorded, and expressed as unit of shell surface area $\left(\mathrm{kg} / \mathrm{cm}^{2}\right)$. The egg shell thickness was measured from the three different parts of shell in each egg (air cell, equator and sharp end) after removing the inner shell membrane using a micrometer screw gauge (Digimatic micrometer, series 293- 330, Mitutoyo, Japan) and the mean value was taken as thickness in millimeter. Haugh units were measured automatically by the formula of Haugh $(\mathrm{HU}=100 \log [($ albumen height +7.57$)-(1.7$ egg weight ${ }^{0.37}$ )])using the multi egg tester (Technical Services and Supplies, TSS, UK) including QCBi digital balance and QCH 
albumen height gauge. Table 1. The ingredient and nutrient composition of experimental diets.

\section{Serum Biochemical Components}

At the end of the experiment ( 60 weeks of age), blood samples were collected from the wing vein of arbitrary selected ten hens from each treatment by $3 \mathrm{~mL}$ sterile syringe. Immediately transfer into non-heparinized blood collection tubes. The collected blood samples were centrifuged at $3,000 \mathrm{rpm}$ for $15 \mathrm{~min}$ at $4^{\circ} \mathrm{C}$, and serum was separated into eppendorf tubes. Thereafter, it stored at $-20^{\circ} \mathrm{C}$ until required for the analysis of biochemical parameters, including albumin (ALB), total protein (TP), cholesterol (CHOL), high-density lipoprotein (HDL), glucose (GLU), triglycerides (TG), aspartate aminotransferase (AST), alanine aminotransferase (ALT), calcium (Ca), phosphorus (P) and alkaline phosphatase (ALP), that were assessed using commercially available diagnostic kits by Konelab 20 Analyzer (Thermo Fisher Scientific, Vantaa, Finland) following the manufacture's instruction guidelines.

\section{Statistical Analysis}

Experimental data were analyzed by ANOVA procedures for one-way completely randomized design using general linear model (GLM) procedure of SAS (SAS 9.1, 2009). Differences among the treatments were tested using Duncan's multiple range tests. A statistical value of $P<0.05$ was regarded as a significant difference and a value of $P<0.10$ was considered indicative of a tendency.

\section{RESULTS}

\section{Performance of Laying Hens}

Effects of dietary AP with or without phytase supplementation on production performances of laying hens over the period from 40 to 60 weeks of age are presented in Table 2. Egg production rate was not affected at the end of each four weeks from 40 to 44,45 to 48 and 49 to 52 weeks of age except for the period at 53 to 56 weeks $(P<0.05)$ and the entire period of 40 to 60 weeks of age $(P<0.01)$. During the entire experiment (40 to 60 weeks), significantly lower egg production was found in hens fed a diet containing $0.20 \% \mathrm{AP}$ while the value was higher in the $0.25 \%$ AP diet with

Table 2. Effect of dietary available phosphorus levels with or without supplementation of phytase on productive performance of laying hens

\begin{tabular}{|c|c|c|c|c|c|c|c|c|}
\hline \multirow{2}{*}{ Parameters } & \multicolumn{3}{|c|}{$\%$ of AP without phytase } & \multicolumn{3}{|c|}{$\%$ of AP with phytase } & \multirow{2}{*}{ SEM } & \multirow{2}{*}{$P$ - value } \\
\hline & 0.20 & 0.25 & 0.30 & 0.20 & 0.25 & 0.30 & & \\
\hline \multicolumn{9}{|l|}{ Egg production (\%) } \\
\hline $40 \sim 44$ weeks & 88.66 & 88.94 & 89.43 & 90.03 & 89.73 & 89.56 & 0.31 & 0.859 \\
\hline $45 \sim 48$ weeks & 85.63 & 86.38 & 87.19 & 87.30 & 88.06 & 87.12 & 0.30 & 0.229 \\
\hline $49 \sim 52$ weeks & 85.44 & 86.64 & 86.90 & 87.22 & 87.93 & 87.33 & 0.34 & 0.419 \\
\hline $53 \sim 56$ weeks & $84.61^{\mathrm{b}}$ & $86.21^{\mathrm{ab}}$ & $86.66^{\mathrm{a}}$ & $87.18^{\mathrm{a}}$ & $87.86^{\mathrm{a}}$ & $86.88^{\mathrm{a}}$ & 0.30 & 0.023 \\
\hline $57 \sim 60$ weeks & 83.19 & 84.64 & 84.86 & 86.10 & 86.97 & 84.89 & 0.40 & 0.095 \\
\hline $40 \sim 60$ weeks & $85.51^{\mathrm{c}}$ & $86.56^{\mathrm{bc}}$ & $87.01^{\mathrm{ab}}$ & $87.59^{\mathrm{ab}}$ & $88.11^{\mathrm{a}}$ & $87.16^{\mathrm{ab}}$ & 0.23 & 0.013 \\
\hline \multicolumn{9}{|l|}{ Egg weight (g) } \\
\hline $40 \sim 44$ weeks & 61.08 & 61.22 & 61.58 & 61.39 & 61.66 & 61.23 & 0.12 & 0.784 \\
\hline $45 \sim 48$ weeks & 61.29 & 61.23 & 61.04 & 60.98 & 61.10 & 61.33 & 0.12 & 0.957 \\
\hline $49 \sim 52$ weeks & 61.24 & 61.21 & 60.82 & 61.44 & 60.83 & 61.02 & 0.14 & 0.801 \\
\hline $53 \sim 56$ weeks & 60.42 & 60.62 & 61.01 & 60.81 & 60.55 & 60.04 & 0.18 & 0.737 \\
\hline $57 \sim 60$ weeks & 61.21 & 60.73 & 60.82 & 61.17 & 60.70 & 61.05 & 0.15 & 0.879 \\
\hline $40 \sim 60$ weeks & 61.05 & 61.00 & 61.05 & 61.16 & 60.97 & 60.93 & 0.07 & 0.974 \\
\hline
\end{tabular}


Table 2. Continued

\begin{tabular}{|c|c|c|c|c|c|c|c|c|}
\hline \multirow{2}{*}{ Parameters } & \multicolumn{3}{|c|}{$\%$ of AP without phytase } & \multicolumn{3}{|c|}{$\%$ of AP with phytase } & \multirow{2}{*}{ SEM } & \multirow{2}{*}{$P$ - value } \\
\hline & 0.20 & 0.25 & 0.30 & 0.20 & 0.25 & 0.30 & & \\
\hline \multicolumn{9}{|l|}{ Egg mass $(\mathrm{g} / \mathrm{h} / \mathrm{d})$} \\
\hline $40 \sim 44$ weeks & 54.16 & 54.44 & 55.06 & 55.26 & 55.32 & 54.84 & 0.22 & 0.632 \\
\hline $45 \sim 48$ weeks & 52.48 & 52.89 & 53.22 & 53.30 & 53.80 & 53.43 & 0.20 & 0.538 \\
\hline $49 \sim 52$ weeks & 52.32 & 53.03 & 52.85 & 53.58 & 53.49 & 53.28 & 0.22 & 0.635 \\
\hline $53 \sim 56$ weeks & 51.11 & 52.26 & 52.87 & 53.01 & 53.19 & 52.16 & 0.23 & 0.081 \\
\hline $57 \sim 60$ weeks & 50.93 & 51.40 & 51.61 & 52.66 & 52.79 & 51.81 & 0.23 & 0.130 \\
\hline $40 \sim 60$ weeks & $52.20^{\mathrm{b}}$ & $52.80^{\mathrm{ab}}$ & $53.12^{\mathrm{ab}}$ & $53.56^{\mathrm{a}}$ & $53.72^{\mathrm{a}}$ & $53.10^{\mathrm{ab}}$ & 0.15 & 0.020 \\
\hline \multicolumn{9}{|l|}{ Feed intake $(g / h / d)$} \\
\hline $40 \sim 44$ weeks & 111.40 & 111.83 & 111.43 & 111.09 & 111.74 & 111.48 & 0.17 & 0.877 \\
\hline $45 \sim 48$ weeks & 112.12 & 112.79 & 113.19 & 112.53 & 113.20 & 112.20 & 0.33 & 0.911 \\
\hline $49 \sim 52$ weeks & 112.86 & 115.09 & 114.18 & 114.56 & 113.75 & 115.68 & 0.60 & 0.844 \\
\hline $53 \sim 56$ weeks & 113.47 & 114.55 & 114.35 & 113.80 & 114.64 & 113.52 & 0.37 & 0.919 \\
\hline $57 \sim 60$ weeks & 113.78 & 113.49 & 113.41 & 114.98 & 114.03 & 114.46 & 0.29 & 0.652 \\
\hline $40 \sim 60$ weeks & 112.72 & 113.55 & 113.31 & 113.39 & 113.47 & 113.47 & 0.16 & 0.744 \\
\hline \multicolumn{9}{|c|}{ Feed conversion ratio ( $g$ of feed consumed/g of egg mass) } \\
\hline $40 \sim 44$ weeks & 2.06 & 2.05 & 2.02 & 2.01 & 2.02 & 2.03 & 0.01 & 0.546 \\
\hline $45 \sim 48$ weeks & 2.14 & 2.13 & 2.13 & 2.11 & 2.10 & 2.10 & 0.01 & 0.843 \\
\hline $49 \sim 52$ weeks & 2.16 & 2.17 & 2.16 & 2.14 & 2.13 & 2.17 & 0.01 & 0.951 \\
\hline $53 \sim 56$ weeks & 2.22 & 2.19 & 2.16 & 2.15 & 2.16 & 2.18 & 0.01 & 0.278 \\
\hline $57 \sim 60$ weeks & 2.23 & 2.21 & 2.19 & 2.18 & 2.16 & 2.21 & 0.01 & 0.320 \\
\hline $40 \sim 60$ weeks & 2.16 & 2.15 & 2.14 & 2.12 & 2.11 & 2.13 & 0.01 & 0.135 \\
\hline
\end{tabular}

SEM, Standard error of the mean; AP, available phosphorus; ${ }^{\mathrm{a} \sim \mathrm{c}}$ Means in the same row bearing different superscript differ significantly; Ronozyme HiPhos-L, 6-phytase produced by the strain of Aspergillus oryzae was used to supply 1,000 FTUkg-1 $\mathrm{of}^{-} \mathrm{feed}$

supplemental phytase when compared that of other dietary treatments. However, there was no consistent difference observed in egg production between hens fed on diets different dietary AP concentrations with phytase. The tendency effect $(P<0.10)$ was found in egg mass by the dietary treatments at 53 to 56 weeks of age and the higher value (53.19 g) was obtained at $0.25 \%$ AP diet with phytase but this effect failed to attain statistical significance. Overall period from 40 to 60 weeks of age, significantly $(P<0.05)$ lower egg mass value obtained when hens were fed $0.20 \%$ AP diet and the higher value was in diets containing 0.20 and $0.25 \%$ AP with phytase. Egg weight, feed intake and feed conversion ratio were not affected among the dietary treatments at the end of each four weeks and over the entire duration of the experiment, regardless of AP levels or phytase supplementation to the diets.

\section{Egg Quality}

Effect of dietary AP levels with or without supplementation of phytase on egg quality traits are presented in Table 3. Statistical analysis of the obtained data revealed that there was no effect on egg shell thickness, egg shell breaking 
Table 3. Effect of dietary available phosphorus levels with or without supplementation of phytase on egg quality of laying hens

\begin{tabular}{|c|c|c|c|c|c|c|c|c|}
\hline \multirow{2}{*}{ Parameters } & \multicolumn{3}{|c|}{$\%$ of $\mathrm{AP}$ without phytase } & \multicolumn{3}{|c|}{$\%$ of AP with phytase } & \multirow{2}{*}{ SEM } & \multirow{2}{*}{$P$ - value } \\
\hline & 0.20 & 0.25 & 0.30 & 0.20 & 0.25 & 0.30 & & \\
\hline \multicolumn{9}{|c|}{ Egg shell thickness (mm) } \\
\hline 44 weeks & 0.353 & 0.355 & 0.349 & 0.349 & 0.354 & 0.354 & 0.002 & 0.943 \\
\hline 48 weeks & 0.364 & 0.369 & 0.365 & 0.362 & 0.360 & 0.357 & 0.002 & 0.583 \\
\hline 52 weeks & 0.345 & 0.364 & 0.356 & 0.352 & 0.361 & 0.354 & 0.002 & 0.340 \\
\hline 56 weeks & 0.342 & 0.346 & 0.356 & 0.348 & 0.351 & 0.349 & 0.001 & 0.423 \\
\hline 60 weeks & 0.349 & 0.364 & 0.361 & 0.358 & 0.354 & 0.359 & 0.002 & 0.408 \\
\hline \multicolumn{9}{|c|}{ Egg shell breaking strength $\left(\mathrm{kg} / \mathrm{cm}^{2}\right)$} \\
\hline 44 weeks & 2.66 & 2.80 & 2.75 & 2.74 & 2.74 & 2.63 & 0.04 & 0.872 \\
\hline 48 weeks & 2.68 & 2.62 & 2.81 & 2.74 & 2.67 & 2.58 & 0.04 & 0.551 \\
\hline 52 weeks & 2.47 & 2.53 & 2.56 & 2.40 & 2.47 & 2.32 & 0.05 & 0.701 \\
\hline 56 weeks & 2.48 & 2.43 & 2.68 & 2.35 & 2.44 & 2.61 & 0.04 & 0.246 \\
\hline 60 weeks & 2.82 & 2.87 & 2.92 & 3.09 & 2.94 & 3.07 & 0.07 & 0.832 \\
\hline \multicolumn{9}{|c|}{ Albumen height (mm) } \\
\hline 44 weeks & 8.46 & 8.32 & 8.57 & 8.51 & 8.22 & 8.20 & 0.08 & 0.708 \\
\hline 48 weeks & 8.09 & 8.04 & 8.20 & 8.03 & 7.93 & 8.19 & 0.08 & 0.927 \\
\hline 52 weeks & 7.84 & 7.44 & 7.83 & 7.48 & 7.76 & 7.43 & 0.09 & 0.489 \\
\hline 56 weeks & 8.80 & 8.85 & 8.83 & 8.75 & 8.80 & 8.35 & 0.08 & 0.425 \\
\hline 60 weeks & 8.21 & 8.02 & 8.28 & 8.47 & 8.22 & 8.03 & 0.09 & 0.738 \\
\hline \multicolumn{9}{|l|}{ Haugh unit score } \\
\hline 44 weeks & 91.20 & 90.10 & 91.73 & 90.74 & 89.64 & 90.01 & 0.44 & 0.744 \\
\hline 48 weeks & 88.52 & 88.63 & 89.46 & 87.65 & 88.02 & 89.17 & 0.45 & 0.872 \\
\hline 52 weeks & 88.06 & 85.61 & 87.29 & 85.44 & 87.67 & 85.95 & 0.50 & 0.503 \\
\hline 56 weeks & 92.69 & 92.88 & 93.20 & 93.26 & 93.94 & 91.24 & 0.44 & 0.630 \\
\hline 60 weeks & 89.62 & 88.60 & 89.66 & 91.08 & 89.94 & 87.93 & 0.52 & 0.596 \\
\hline
\end{tabular}

SEM, Standard error of the mean; AP, available phosphorus; Ronozyme HiPhos-L, 6-phytase produced by the strain of Aspergillus oryzae was used to supply $1,000 \mathrm{FTUkg}^{-1}$ of feed.

strength, albumen height and Haugh unit by dietary treatments when evaluated at the end of every four weeks during the study for twenty weeks.

\section{Serum Biochemical Components}

The effect of experimental diets on serum biochemical parameters of laying hens are shown in Table 4. In this study, there was no consistent effect of dietary AP concentrations either between with or without supplemental phytase on ALB, TP, GLU, CHOL, HDL, TG, ALT and AST levels in serum observed. However, the addition of phytase to the AP containing diets did not significantly affect serum $\mathrm{Ca}$ and $\mathrm{P}$ concentration but it did increase linear numerically for dietary levels of AP from 0.20 to $0.30 \%$ with phytase when evaluated without supplemental phytase groups. The ALP level in serum had a tendency $(P<0.10)$ to decrease linearly by the addition 
Table 4. Effect of dietary available phosphorus levels with or without supplementation of phytase on serum biochemical components of laying hens at 60 weeks

\begin{tabular}{|c|c|c|c|c|c|c|c|c|}
\hline \multirow{2}{*}{ Parameters } & \multicolumn{3}{|c|}{$\%$ of AP without phytase } & \multicolumn{3}{|c|}{$\%$ of AP with phytase } & \multirow{2}{*}{ SEM } & \multirow{2}{*}{$\begin{array}{c}P \text { - } \\
\text { value }\end{array}$} \\
\hline & 0.20 & 0.25 & 0.30 & 0.20 & 0.25 & 0.30 & & \\
\hline $\mathrm{ALB} \quad(\mathrm{mg} / \mathrm{dL})$ & 2.06 & 2.19 & 1.96 & 2.14 & 2.06 & 2.02 & 0.04 & 0.744 \\
\hline $\mathrm{TP}(\mathrm{mg} / \mathrm{dL})$ & 5.97 & 6.27 & 5.59 & 6.98 & 5.92 & 5.92 & 0.19 & 0.383 \\
\hline $\mathrm{CHOL}(\mathrm{mg} / \mathrm{dL})$ & 161.94 & 155.18 & 152.55 & 159.35 & 151.12 & 146.42 & 6.42 & 0.989 \\
\hline HdL (mg/dL) & 9.26 & 7.68 & 9.01 & 7.14 & 7.79 & 8.25 & 0.55 & 0.891 \\
\hline GLU (mg/dL) & 259.25 & 263.81 & 279.18 & 254.75 & 273.44 & 268.40 & 4.25 & 0.607 \\
\hline ALT (IU/L) & 1.27 & 1.03 & 0.86 & 0.89 & 1.33 & 0.85 & 0.14 & 0.898 \\
\hline AST (IU/L) & 175.38 & 185.53 & 171.67 & 166.51 & 190.21 & 161.32 & 5.01 & 0.565 \\
\hline $\mathrm{TG}(\mathrm{mg} / \mathrm{dL})$ & $1,877.33$ & $1,579.06$ & $1,463.60$ & $1,721.28$ & $1,456.62$ & $1,450.97$ & 93.69 & 0.742 \\
\hline $\mathrm{P}(\mathrm{mg} / \mathrm{dL})$ & 5.36 & 5.87 & 6.02 & 6.17 & 6.56 & 7.03 & 0.25 & 0.536 \\
\hline $\mathrm{Ca}(\mathrm{mg} / \mathrm{dL})$ & 16.54 & 17.07 & 17.38 & 17.91 & 18.89 & 19.07 & 0.42 & 0.459 \\
\hline ALP (IU/L) & 455.01 & 418.41 & 397.56 & 392.87 & 370.83 & 358.21 & 10.25 & 0.066 \\
\hline
\end{tabular}

SEM, Standard error of the mean; AP, available phosphorus; ALB, albumin; TP, total protein; CHOL, cholesterol; HDL, high density-lipoprotein; GLU, glucose; ALT, alanine aminotransferase; AST, aspartate aminotransferase; TG, triglycerides; Ca, calcium; P, phosphorus; ALP, alkaline phosphatase; Ronozyme HiPhos-L, 6-phytase produced by the strain of Aspergillus oryzae was used to supply $1,000 \mathrm{FTUkg}^{-1}$ of feed.

of phytase into the diets when did compare that were not supplemented phytase.

\section{DISCUSSION}

Phytase enzymes are being extensively used in diet as dietary feed additives in order to increase the digestibility of phytate $\mathrm{P}$ and positively influence the digestibility of other nutrients. The beneficial effect of phytase supplementation on layers has been studied by numerous investigations but it is still going discussion into the researchers because there could not be found general resemble from related literature regarding the dietary level of AP with inclusion level of phytase in laying performance. As a result, in this study, we have explored the impact of dietary variation levels of AP with or without phytase supplementation in commercial layer diets during several age periods at the second production phase. The results of the current experiment showed that the addition of phytase into the basal diet containing levels of 0.20 to $0.30 \%$ AP increased egg production of laying hens in comparison to respective AP diets that were not supplemented phytase during overall period of the experiment from 40 to 60 weeks of age. Although, there was no consistent difference obtained in egg production between 0.25 to $0.30 \%$ AP diet and supplementation of phytase in 0.20 to $0.30 \%$ AP diets but numerically higher egg production was obtained due to hens fed $0.25 \%$ AP diet with phytase when compared with all other dietary treatments. This finding is in consistent with the findings of Englmaierova et al. (2014) who showed that the dietary level of $0.17 \%$ AP or $0.21 \%$ AP diet with phytase supplementation significantly improved egg production of laying hens than that of without phytase from 37 to 49 weeks of age, whereas similar to those obtained for the diet of $0.30 \%$ AP with or without phytase. Silversides and Hruby (2009) reported that the egg production increased with the supplementation of phytase into the laying hens diet when hens were fed either $0.19 \%$ AP or $0.22 \%$ AP diet from 45 to 60 weeks of age as compared with performance of hens fed a control diet containing $0.34 \%$ AP. Moreover, similar to the current experiment, it has shown that phytase supple- 
mentation to the control diet $0.45 \%$ AP and the low $0.30 \%$ AP diet significantly increased egg production from 75.49 to $77.96 \%$ and from 64.59 to $76.54 \%$ respectively (Cabuk et al., 2004). In the present study, it also showed that egg production of hens receiving $0.20 \%$ AP was significantly lower than those given higher AP diet $(0.25$ or $0.30 \%)$. It demonstrates that $0.20 \%$ AP was insufficient to provide the daily $\mathrm{P}$ requirement of laying hens. This adverse effect was completely corrected by phytase supplementation that may have helped to increase absorption of nutrients resulting that corrected egg production. Previous studies have reported that supplementing a diet containing 0.12 to $0.20 \%$ AP with phytase resulted in a significant improvement in laying egg production when compared with the same diet that was not supplemented with phytase (Hughes et al., 2008; Yan et al., 2009; Rojas et al., 2017). It is conceivable therefore that the improvement in egg production of laying hens which might have been due to increased availability of $\mathrm{P}$ and eliminating the anti-nutritive effect of phytate on digestibility of other nutrients by phytase (Lei et al., 2011). Egg weight is the elementary trait to assess egg quality. In the present study, egg weight was not affected by AP concentrations and supplementation of phytase into the diet, which implies that the dietary lowest level of $0.20 \% \mathrm{AP}$ was adequate to maintain egg weight during the period of 40 to 60 weeks of age, even in supplementation of phytase. Similar to previous findings, no significant effect of AP concentration and phytase supplementation on egg weight was reported in laying hens between 32 to 48 or 62 weeks of age (Panda et al., 2005; Meyer and Parsons, 2011; Englmaierova et al., 2014). In the present study at 40 to 60 weeks, egg mass was significantly lower for hens fed $0.20 \%$ AP diet without phytase, whereas diet with $0.20 \%$ AP plus phytase had equal egg mass to the 0.25 and $0.30 \%$ AP diets with or without phytase. Similar to these findings, Englmaierova et al. (2014) reported that the addition of phytase to the diet containing $0.21 \%$ AP improved egg mass of laying hens which was alike to the diet containing $0.30 \%$ AP with or without phytase. The results regarding the egg mass was also agreement with those obtained by $\mathrm{Wu}$ et al. (2006) reported that phytase supplementation significantly improved egg mass in the diets containing $0.11 \%$ AP, but had no effect on egg mass for the diet containing $0.26 \%$ AP. Thus, the improvement of egg mass value during the entire experiment in this study which may have associated with increase egg production rate of hens due to supplemental phytase into the diets. The present study demonstrated that feed consumption of laying hens by dietary AP concentrations had similar to those fed same diets that were supplemented phytase and hence the lowest concentration of $0.20 \%$ AP diet, which may be optimum during this period. Results regarding the feed intake of laying hens is in agreement with those obtained by Hughes et al. (2008) who reported that hens from 21 to 61 weeks of age fed diets containing 0.15 to $0.25 \%$ AP with supplemental phytase did not affect the feed consumption of laying hens that was similar to those of hens fed a diet containing $0.35 \%$ AP. Baghban-Kanani et al. (2020) who found that there was no significant effect on feed consumption of laying hens in response to phytase supplementation in the diet containing $0.30 \%$ AP from 56 to 65 weeks of age. Also concurrent of these observations, Meyer and Parsons (2011) and Wang et al. (2013) did not find significant effect of phytase supplementation on feed consumption in laying hens. There was no difference in feed conversion ratio due to addition of phytase in the diets. The feed utilization efficiency of laying hens is closely related to feed intake, egg mass output, egg weight and egg production. Although in this study during the whole experimental period there was significant difference in the egg production and egg mass output but did not affect other performance traits in laying hens. It is suspected that the addition of phytase in the diets having the same effect in helping the absorption of proteins and lipids in the digestive tract, so that the resulting weight of the eggs had almost the same between treatments. Egg weight ratio similar to feed consumption did not provide a significant effect on feed utilization efficiency variations. The results regarding the feed conversion ratio are in agreement with those obtained by Wang et al. (2013) who reported that the addition of phytase into the laying hen diet containing level of 0.16 to $0.26 \% \mathrm{AP}$ had not differed feed conversion that were similar to those of hens fed a diet containing $0.36 \%$ AP where phytase was not added, from 44 to 55 weeks of age. Similarly, Meyer and 
Parsons (2011) reported that the feed utilization efficiency of laying hens fed diets containing either $0.20 \%$ AP or $0.11 \%$ AP supplemented with phytase was not significantly different from that of hens fed a diet containing $0.45 \%$ AP from 32 to 62 weeks of age.

No improvement in egg quality traits as observed in this study which was unexpected. Regarding this fact, earlier studies have shown that incorporation of phytase into the diet improved egg shell quality, especially egg shell thickness and egg shell breaking strength which could probably be associated for the consequence of increased divalent mineral utilization such $\mathrm{Ca}$ and $\mathrm{P}$ retention through the metabolic process by reducing the formation of insoluble mineral phytate complexes (Lim et al., 2003; Liu et al., 2007; Zyla et al., 2011). However, the current study findings were concomitant with Kim et al. (2017) reported that egg quality traits including egg shell thickness and egg shell breaking strength were not influenced for hens fed diet containing $0.26 \%$ AP supplemented with phytase which was similar to those obtained either with $0.26 \%$ AP or $0.38 \%$ AP where did not supplement phytase, and suggesting that which might be due to adequate concentrations of $\mathrm{Ca}$ and $\mathrm{P}$ present in the diets. Similarly, Wang et al. (2013) reported that there was no significant difference between the dietary treatments for egg shell thickness and egg shell breaking strength when hens were fed diets containing $0.16 \%$ to $0.26 \%$ AP supplemented with phytase and the diet containing $0.36 \%$ AP. Thus, it may be speculated that based on the observation for similar feed intake in diets either with the presence or absence of phytase, $\mathrm{Ca}$ and $\mathrm{P}$ concentrations in these diets were sufficient to support proper egg shell formation during this phase.

In the current study, serum $\mathrm{Ca}$ and $\mathrm{P}$ level had linear numerically increased trend in laying hens due to the phytase addition with dietary AP concentrations but did not reach significant level among the treatments. The numerically increase these values in serum which could probably be attributed by the hydrolysis of phytate due to addition of phytase in the diets, which might have helped to digest and absorb $\mathrm{Ca}$ and $\mathrm{P}$ that might be correlated with egg production. The results regarding the serum $\mathrm{P}$ which partly agreement with the findings of Silversides et al. (2006) who reported that phytase supplementation in laying hens diet increased serum P level from $5.17 \mathrm{mg} / \mathrm{dl}$ (with no phytase addition to diets) to $6.3 \mathrm{mg} / \mathrm{dl}$ with addition of phytase. Similarly, Rama-Rao et al. (1999) who reported that the P increased linearly in response to phytase supplementation. The results regarding the serum $\mathrm{Ca}$ are being supported by data obtained by Hassanien and Elnagar (2011) who reported that serum $\mathrm{Ca}$ concentration increased with the supplementation of phytase and indicating that phytase can improve Ca bioavailability in laying hens. As the scientific literature it is noted that, a higher phytate might be responsible for the higher ALP activity in the plasma is associated with intestinal lesions, skeletal disorder or liver dysfunction and also may be related to $\mathrm{Ca}$ or $\mathrm{P}$ deficiency or excess $\mathrm{Ca}$ and $\mathrm{P}$ ratio in diet. In this study, a linear tendency to decrease ALP concentration in serum due to phytase addition with the dietary AP levels observed, which might be reflected in the increased availability of P. In a way, in agreement with the current study, it has been found that supplemental phytase to the diets caused a decrease serum ALP concentration in laying hens (Musapuor et al., 2005) and broilers (Farhadi et al., 2017), thereby might have increased $P$ availability. In the previous study, Attia et al. (2010) who reported that the serum concentration of total protein, cholesterol, aspartate amino transferase, alanine amino transferase, cholesterol and triglyceride were not influenced by phytase supplementation into the diets of laying hens, which were concomitant with the results of current study.

On the basis of these results, it is concluded that supplementation of phytase into the diet of laying hens have positively significant influence effect on egg production, egg mass output and has a tendency effect to decrease serum ALP concentration which may indicate increase $\mathrm{P}$ availability, also led to being numerically increased $\mathrm{Ca}$ and $\mathrm{P}$ in serum. However, with respect to egg production, the diet containing $0.20 \%$ AP with phytase is sufficient to maintain optimum egg production during the second production period of laying hens. Moreover, further follow up studies are required in this regard to investigate the layer performance, egg quality parameters, serum biochemical traits, mineral 
retention and cell-mediated immunity of egg-type birds.

\section{ACKNOWLEDGEMENTS}

This research was supported by "Cooperative Research Program of Agriculture Science and Technology (PJ0194 0202)" Rural Development Administration, Republic of Korea, and Korea Institute of Planning and Evaluation for Technology in Food, Agriculture and Forestry (IPET) through Agriculture, Food and Rural Affairs Convergence Technologies Program for Educating Creative Global Leader, funded by Ministry of Agriculture, Food and Rural Affairs (MAFRA; 716002-7).

\section{ORCID}

Chun Ik Lim https://orcid.org/0000-0003-0386-5694

Md Masud Rana https://orcid.org/0000-0003-1410-054X

Hwan Ku Kang https://orcid.org/0000-0002-4286-3141

Kyeong Seon Ryu https://orcid.org/0000-0002-3246-8412

\section{REFERENCES}

Adeola O, Cowieson AJ 2011 Opportunities and challenges in using exogenous enzymes to improve non-ruminant animal production. J Anim Sci 89(10):3189-3218.

Attia YA, Qota EM, Bovera F, Tag EI-Din AE, Mansour SA 2010 Effect of amount and source of manganese and/or phytase supplementation on productive and reproductive performance and some physiological traits of dual purpose cross-bred hens in the tropics. Br Poult Sci 51(2):235-245

Baghban-Kanani P, Hosseintabar-Ghasemabad B, AzimiYouvalari S, Seidavi A, Laudadio V, Mazzei D, Tufarelli V 2020 Effect of dietary sesame (Sesame indicum L.) seed meal level supplemented with phytase lysine and phytase on performance traits and antioxidant status of late phase laying hens. Asian-Aust J Anim Sci 33(2): 277-285.

Butani J, Parnerkar S 2015 Role of microbial phytase in broiler nutrition -a review. J Livest Sci 6(1):113-118.

Cabuk M, Bozkurt M, Kirkinar F, Ozkul H 2004 Effect of phytase supplementation of diets with different levels of phosphorus on performance and egg quality of laying hens in hot climatic condition. S Afr J Anim Sci 34(1):13-17.

Cowieson AJ, Bedford MR 2009 The effect of phytase and carbohydrase on ileal amino acid digestibility in monogastric diets: complimentary mode of action? Worlds Poult Sci J 65(4):609-624.

Dersjant-Li Y, Awati A, Schulze H, Partridge G 2015 Phytase in non-ruminant animal production: a critical review on phytase activities in the gastrointestinal tract and influencing factors. J Sci Food Agric 95(5):878-896.

Englmaierova M, Skrivanova V, Skrivan M 2014 The effect of nonphytate phosphorus and phytase levels on performance, egg and tibia quality, and $\mathrm{pH}$ of the digestive tract in hens fed higher calcium content diets. Czech $\mathrm{J}$ Anim Sci 59(3):107-115

Farhadi D, Karimi A, Sadeghi G, Rostamzadeh J, Bedford MR 2017 Effect of a high dose of microbial phytase and myo-inositol supplementation on growth performance, tibia mineralization, nutrient digestibility, litter moisture content, and foot problems in broiler chickens fed phosphorus-deficient diets. Poult Sci 96(10):3664-3675.

Gao CQ, Ji C, Zhang JY, Zhao LH, Ma QG 2013 Effect of a novel plant phytase on performance, egg quality, apparent ileal nutrient digestibility and bone mineralization of laying hens fed corn-soybean diets. Anim Feed Sci Tech 186(1):101-105.

Hassanien HHM, Elnagar SHM 2011 Comparison difference levels of phytase enzyme supplementation on laying hen performance, egg quality and some blood parameters. Asian J Poult Sci 5(2):77-85.

Hughes AL, Dahiya JP, Wyatt CL, Classen 2008 The efficacy of quantum phytase in a forty-week production trial using White Leghorn laying hens fed corn-soybean meal based diets. Poult Sci 87(6):1156-1161.

Jing M, Zhao S, Rogiewicz A, Slominski BA, House JD 2018 Assessment of the minimal available phosphorus needs of laying hens: implications for phosphorus management strategies. Poult Sci 97(7):2400-2410.

Kim JH, Pitargue FM, Jung H, Han GP, Choi HS, Ki DY 2017 Effect of superdosing phytase on productive performance and egg quality in laying hens. Asian-Aust $\mathrm{J}$ Anim Sci 30(7):994-998. 
Lei QB, Shi LX, Zhang DKY, Ding XM, Bai SP, Liu YG 2011 Effect of reduced energy, protein and entire substitution of inorganic phosphorus by phytase onperformance and bone mineralization of laying hens. Br Poult Sci 52(2):202-213.

Lim HS, Namkung H, Paik IK 2003 Effects of phytase supplementation on the performance, egg quality and phosphorus excretion of laying hens fed different levels of dietary calcium and non-phytate phosphorus. Poult Sci 82(1):92-99.

Liu N, Liu GH, Li FD, Sands JS, Zhang S, Zheng AJ 2007 Efficacy of phytase on egg production and nutrient digestibility in layers fed reduced phosphorus diets. Poult Sci 86(11):2337-2342.

Meyer E, Parsons C 2011 The efficacy of phytase enzyme fed to Hy-line W-36 laying hens from 32 to 62 weeks of age. J Appl Poult Res 20(2):136-142.

Musapuor A, Pourreza J, Samie A, Mordai SH 2005 The effects of phytase and different level of dietary calcium and phosphorus on phytate phosphorus utilization in laying. Int J Poult Sci 4(8):560-562.

NRC 1994 Nutrient Requirements of Poultry, 9th revised edition, National Academy Press, Washington, DC USA.

Panda AK, Rama Rao SV, Raju MVLN, Bhanja SK 2005 Effect of microbial phytase on production perforamce of white leghorn layers fed on a diet low in non-phytate phosphorus. Br Poult Sci 46(4):464-469.

Rama Rao SV, Reddy VR, Ravindran R 1999 Enhancement of phytate phosphorus availability in the diets of commercial broilers and layers. Anim Feed Sci Tech 79(3): 211222.

Rojas IYM, Gonzalez EA, Menocal JA, Santos TTD, Arguello JR, Coello CL 2017 Assessment of a phytase included with lactic acid on productive parameters and on deposition of phosphorus, calcium, and zinc in laying hens fed with sorghum soybean meal based diets. J Appl Anim Res 46(1):314-321.

Silversides FG, Hruby M 2009 Feed formulation using phytase in laying hen diets. J Appl Anim Res 18(1):15-22.

Silversides FG, Scoot TA, Korvert DR, Afsharmanes MH, Hruby M 2006 A study on the interaction of xylanase and phytase enzymes in wheat-based diets fed to commercial white and brown egg laying hens. Poult Sci 85(2):297-305.

Slominski BA 2011. Recent advances in research on enzymes for poultry diets. Poult Sci 90(9):2013-2023.

Sousa JPL, Albino LFT, Vaz RGMV, Rodrigues KF, Da Silva GF, Renno LN, Barros VRSM, Kaneko IN 2015 The effect of dietary phytase on broiler performance and digestive, bone, and blood biochemistry characteristics. Braz J Poultry Sci 17(1):69-76.

Wang S, Tang CH, Zhang JM, Wang XQ 2013 The effect of dietary supplementation with phytase transgenic maize and different concentration of non-phytate phosphorus on the performance. Br Poult Sci 54(4):466-470.

Wu G, Liu Z, Bryant MM, Roland DA 2006 Comparison of natuphos and phyzyme as phytase sources for commercial layers fed corn-soy diet. Poult Sci 85(1):64-69.

Yan L, Zhou TX, Jang HD, Hyun Y, Kim HS, Kim IH 2009 Comparative effects of phytase derived from Escherichia coli and Aspergillus niger in sixty-eight weeks old laying hens fed corn-soy diet. Asian-Aust J Anim Sci 22(10): 1391-1399.

Zyla K, Mika M, Swiatkiewiczs S, Koreleski J, Piironen J 2011 Effects of phytase $\mathrm{B}$ on laying performance, egg shell quality and on $\mathrm{P}$ and $\mathrm{Ca}$ balance in laying hens fed P-deficient maize-soybean meal diets. Czech J Anim Sci 56(9):406-413.

Received May 18, 2020, Revised Aug. 31, 2020, Accepted Dec. 26, 2020 
